TEMPUS. Revista en Historia General Medellín (Colombia), 2018, septiembre-octubre, número 8

ISSN: 2422-2976

\title{
GOLETA Y BALANDRA. (DE)COMISO, MANEJO Y REGISTRO DE EMBARCACIONES EXTRANJERAS EN EL NORTE DE SURAMÉRI- CA DURANTE EL PERIODO TARDÍO COLONIAL
}

GOLETA AND BALANDRA. (DE) COMMISSION, MANAGEMENT AND REGISTRATION OF FOREIGN VESSELS IN NORTH OF SOUTH AMERICA DURING THE COLONIAL LATE PERIOD

Carlos Mario Atehortúa Meneses ${ }^{1}$

Universidad de Antioquia

DOI: 10.17533/udea.tempus.n8a06

\section{Resumen}

Este documento busca describir desde la perspectiva de la historia social las implicaciones de los comisos realizados en el Virreinato del Nuevo Reino de Granada. Actividad que se basaba en el patrullaje guardacostas pero que, no estaba supeditada a estos, ni tampoco al área marítima o la franja costera. Para tal fin empezaremos describiendo la formación de la defensa naval, con sede en Cartagena de Indias y las innovaciones durante el periodo borbónico. Después analizaremos la dinámica de comisos y los fenómenos subyacentes, así como las relaciones formadas entorno a esta acción durante el siglo XVIII.

Palabras clave: comisos, guardacostas, Caribe, Imperio español.

\begin{abstract}
This document seeks to describe from the perspective of social history the implications of the confiscations made in the Viceroyalty of the New Kingdom of Granada. Activity that was based on coastguard patrols but that was not subject to them, nor to the maritime area or the coastal strip. For this purpose we will begin by describing the formation of the naval defense, based in Cartagena de Indias and the innovations during the Bourbon period. Then we will analyze the dynamics of confiscations and the un-
\end{abstract}

${ }^{1}$ Historiador, miembro oficial Grupo Investigación Historia Social (GIHS), Universidad de Antioquia. Medellín, Colombia. buzzondecarlos@gmail.com 
derlying phenomena, as well as the relationships formed around this action during the 18 th century.

Keywords: confiscations, coastguard, Caribbean, Spanish Empire.

\section{Introducción}

El proyecto monopolista que los Austrias habían querido implementar en las Indias occidentales ya era cosa del pasado. Desde un inicio, para la empresa colonial las autoridades hispanas implementaron un sistema comercial basado en flotas convoyadas de galeones que cumplían el tránsito a través del Atlántico. Su defensa se encargó durante el siglo XVI y mediados del XVII a las galeras que surcaron las costas de la península ibérica y el Mediterráneo, sobre todo. Estas embarcaciones, por momentos sirvieron en el resguardo del contorno costero del norte de Suramérica, donde establecieron base en Cartagena de Indias, por lo general en escuadras formadas por uno o dos pares. Realizando desde allí patrullajes en un perímetro que siempre buscó cubrir las zonas del Darién y la costa de Mosquitos en Centroamérica y hacía el oriente hasta Venezuela, la Guayana y la isla de Trinidad. El crecido gasto que representaba el mantenimiento de las galeras y su progresivo aventajamiento por parte de embarcaciones de otra clase construidas en España y el norte de Europa especialmente; al final terminó por llevar estos navíos al desuso dentro de la estrategia principal de defensa del imperio español. Claro que, no sin haber servido antes, en el objetivo de la monarquía católica de frenar el avance otomano y sus pretensiones atlánticas. ${ }^{2}$

A mediados del siglo XVI se lograron avances en un prototipo de barco que combinara capacidad de carga y poder de fuego de artillería, estos iban a ser los primeros galeones. ${ }^{3}$ Sostenía esta red, un grupo selecto de cargadores y armadores. La balanza comercial, que beneficiaba a los comerciantes peninsulares y a la corona española implicaba el canje de mercaderías europeas de todo tipo por metales y géneros de la tierra coloniales. En las ciudades del norte de Suramérica como Cartagena de In-

\footnotetext{
${ }^{2}$ Sebastián Amaya Palacios, "Poderío naval en las Indias: las galeras de Cartagena y Manila (1571-1621)", RESI 3, n.2 (2017): 175.

${ }^{3}$ José Luis Casado Soto, "El Cantábrico y las galeras hispanas de la Edad Media a la Moderna", Itsas memoria, n.4 (2003): 549.
} 
TEMPUS. Revista en Historia General Medellín (Colombia), 2018, septiembre-octubre, número 8

ISSN: 2422-2976

dias, Santa Marta o Riohacha se establecían factores o agentes comerciales que servían de enlace entre los comerciantes locales y la metrópoli, entre estos se contaban súbditos portugueses y de otras naciones, incluso judíos y protestantes, algo impensable. ${ }^{4}$ Rápidamente las demás naciones del mundo quisieron disputarle a España el privilegio de comercio con América, no solo iban a ser los piratas, lobos de mar que no reconocían más que su propia ley y potestad; a la hora de las operaciones de saqueo y repartición del botín.

En el Caribe también patrullaban navíos autorizados por monarquías europeas que teniendo el patrocinio y la gracia real recibían patente de corso para acechar embarcaciones y asentamientos de bandera española, que eran apetecidos por la promesa de riquezas coloniales. También hubo bucaneros y después filibusteros, que surcaron entre las Antillas a bordo de sus veloces navíos. A medida que se fue sucediendo la rapiña los enemigos acérrimos de España se hicieron con posiciones que resultarían estratégicas para, desde allí despachar expediciones o almacenar mercadurías para su introducción ilícita en las colonias americanas; de igual manera se desarrolló una explotación intensiva de cultivos de valor asegurado como el azúcar o el tabaco. Sirviendo de vanguardia-punta de lanza, carne de cañón de las potencias europeas, las distintas manadas de lobos de mar dieron paso a una ocupación de facto de territorios que habían sido dejados de lado por España, debido a la incapacidad para asegurarlos o a dificultades para ocuparlos adecuadamente. Incluso, naciones de un perfil más reservado como Suecia, Dinamarca o Prusia se abalanzaron en la toma de partido; en su caso los daneses se ubicaron en Saint Thomas desde donde lograrían el control de gran parte de las Islas Vírgenes, un territorio que denominaron Jomfruøerne. ${ }^{5}$

El legado de los Austria llegó al final con la muerte de Carlos II al que, a pesar de su plan para sanear las finanzas de los asientos para la construcción de embarcacio-

\footnotetext{
${ }^{4}$ Entre la comunidad judaizante en Cartagena de Indias empezó a tener lugar un punto de aprovisionamiento e intercambio con sede en Amsterdam, la Jerusalén del norte. Ricardo Escobar, "Los criptojudios de Cartagena de Indias: un eslabón en la diáspora conversa", Anuario colombiano de historia social y de la cultura, n. 29 (2002): 55.

5 Ángel Francisco Manzanilla Celis, "Los guardacostas de Cartagena de Indias y la defensa del virreinato del Nuevo Reino de Granada. 1788-1808", (tesis de doctorado, Universidad de Sevilla, 2013), 157.
} 
nes, solamente sobrevivió una fuerza naval compuesta -además de otras cuantas unidades- por siete galeras. ${ }^{205}$ La Guerra de Sucesión, dio paso a una alianza entre Francia y España casi asegurada hasta la Revolución de 1796. Pero también, Inglaterra resultó fortalecida con la oportunidad de dictar condiciones para reconocer el reinado de Felipe de Anjou. Iba a ser mediante los tratados de Utrecht que se terminaría implantando el nuevo sistema diseñado por los ingleses, uno en el que predominara la competencia comercial y donde ya no eran necesarias las prácticas de abordaje en costas y aguas americanas. ${ }^{206}$ Las Provincias Unidas, por su parte parecen haberse decidido por el contrabando de forma rotunda y dejar de lado la posesión territorial; tras una guerra de desgaste económico con Inglaterra durante buena parte del siglo XVII y a pesar de una aparente expansión mediante la conquista de Nueva Suecia, las colonias holandesas en los ríos Hudson y Delaware fueron cedidas a los ingleses y los portugueses se apoderaron de posiciones neerlandesas en África, Brasil y la Guayana. Para 1700 los restos de este imperio colonial consistían básicamente en las islas de San Eustaquio y Tobago en las Antillas, una Curazao predominante y una red de plantaciones en la Guayana y en Elmina, África. Desde estos puestos devenidos en bases comerciales, los holandeses articulaban el aprovisionamiento de esclavos y mercancías. ${ }^{8}$ En medio del despojo comercial de sus enemigos, España al ser incapaz de mantener una administración efectiva de sus colonias dio paso a la proliferación del contrabando. ${ }^{9}$ Limitándose con implementar medidas paliativas, como la apertura del comercio a las naciones neutrales. ${ }^{10}$ La Guerra de Sucesión redujo al mínimo la armada española, al punto de cortar las comunicaciones e impedir que fueran despachadas mercancías desde la península.

\footnotetext{
${ }^{6}$ Jesús Pradells Nadal, "La formación de la Marina española en el siglo XVIII”, Canelobre, n. 51 (2006): 46.

${ }^{7}$ Antonio García de León, "Comercio de balandra, contrabando y piratería en el Golfo de México", Orbis incognitvs avisos y legajos del Nuevo Mundo: homenaje al profesor Luis Navarro García, coord. Fernando Navarro Antolín (Huelva: Universidad de Huelva, 2007), 187.

${ }^{8}$ David Fieldhouse, Los imperios coloniales antes de 1815”, Los imperios coloniales desde el siglo XVIII (México: Siglo XXI Editores, 1984), 37-38.

${ }^{9}$ Isabel E. Ruiz A. "Breve esbozo sobre el comercio ilícito cumanés durante el siglo XVIII", Mañongo 30, n. 16 (2008): 169.

${ }^{10}$ Ana Johana S. Vergara, "Los vínculos entre la provincia de Caracas y la isla caribeña de San Thomas durante las guerras de independencia (1808-1821)", Anuario de estudios bolivarianos, n. 17 (2010): 176.
} 
TEMPUS. Revista en Historia General Medellín (Colombia), 2018, septiembre-octubre, número 8

ISSN: 2422-2976

Mientras tanto, los ingleses saciaban la demanda americana. En 1717 José Patiño fue nombrado en España, Intendente General de Marina, para gestionar la reactivación de la armada y el intercambio con las Indias. ${ }^{11}$ El Proyecto para Galeones y Flotas fue incorporado en 1720 y pretendía poner de nuevo en marcha los negocios y la recaudación de impuestos, pero al arribar los galeones a Tierra Firme encontraron que los puertos ya habían sido abastecidos porque "pequeños navíos holandeses e ingleses se les habían adelantado". ${ }^{12}$ Algo que dejó bastante mal paradas a las autoridades del recién formado Virreinato del Nuevo Reino de Granada, en cuanto a la gestión de uno de los objetivos principales de su establecimiento, el combate del comercio ilegal; tanto que sería disuelto en 1723. El sistema trató de mejorarse introduciendo navíos de correo que mantuvieran informados regularmente a los cargadores en España acerca de la demanda y el nivel de los precios en América, así como en el Nuevo Mundo de la llegada de la flota. Incluso, en 1735 comenzaron a permitirse por parte de las autoridades borbónicas la entrada de barcos individuales, "registros sueltos" para abastecer la demanda. Pero, las flotas continuarían en medio de las dificultades, uno de los últimos testigos de la situación comercial española en Indias sería justamente don Blas de Lezo. Quien, al mando de un convoy llegó al Nuevo Mundo en 1737, para comprobar que sería muy complicado vender su carga, porque en Portobelo y Cartagena el mercado "estaba saturado". Apenas arribó al Virreinato del Nuevo Reino de Granada se puso a dar paso a los preparativos para el establecimiento de una renovada fuerza de guardacostas en el norte de Suramérica.

Desde el Renacimiento se venía instalado una corriente de mejoramiento técnico que originó avances significativos en los diseños de las embarcaciones a partir de la galera y el galeón, algo en lo que ciertamente las naciones del norte de Europa comenzaron a adelantar a España. Entre las unidades que alcanzó a preparar Blas de Lezo para realizar el patrullaje de las aguas en la jurisdicción del Virreinato, esta vez predominaban los navíos de vela, de bordo alto y gran calado; capaces de soportar varias

\footnotetext{
${ }^{11}$ Alfredo José Martínez González, "Bosques y política naval atlántica: las reformas normativas e institucionales de José Patiño (1717-1736)", Revista hispanoamericana, n. 3 (2013): 3-4.

${ }^{12}$ Miguel Malagón Pinzón, "El consulado de comercio de Cartagena", Estudios socio-jurídicos 13, n. 2 (2001): 54.
} 
unidades de artillería. Aunque con dificultad, la escuadra estuvo compuesta de goletas, bergantines y balandras. ${ }^{13}$ Las murallas y embarcaciones de Cartagena de Indias sirvieron para repeler a Vernon, que le puso sitio en 1741, así España seguiría teniendo el dominio de Tierra Firme por lo menos medio siglo más. Pero todos los navíos que defendían la costa quedaron destruidos, por lo que el contrabando alcanzó mayor difusión después de la Guerra del Asiento. ${ }^{14}$ Sin embargo, las raíces del sistema de salvaguarda costera durante el dominio borbón quedaron establecidas. En 1750 la corona española aprobó la creación de un Apostadero en el barrio Getsemaní, al que se nombró el Boquete. Aunque, en realidad los trabajos para habilitar almacenes, talleres y muelles concluirían apenas en 1786, pero el objetivo era poder contar en la ciudad con un sitio para atender especialmente a los barcos de guerra que se encargarían de combatir el contrabando de mercancías y proteger al puerto. ${ }^{15}$ El final del Asiento con los ingleses dio la oportunidad a España para desplegar un plan de recuperación del comercio y la recaudación fiscal. Ahora, un sistema de navíos individuales, registros sueltos provocarían el aumento paulatino de las transacciones hasta 1778 y también la integración de pequeños centros de abastecimiento que ampliaron el mercado de intercambios. $^{16}$

Para enfrentar el contrabando se implementaron los comisos de guardacostas, asunto sobre el que versa el presente estudio. Con seguridad, todos los temas tratados hasta el momento han sido estudiados ya por investigadores de todas partes del mundo, en el debate de los comisos los aportes dentro del contexto colonial borbónico han tenido lugar de manera más visible desde México y la zona norte del Gran Caribe; en donde resaltan los estudios del Dr. Julio César Rodríguez Treviño. O para el Virreinato del Rio de la Plata, que están representados en el trabajo conjunto de algunos historiadores, ciertamente llegados a tal asunto de manera colateral. ${ }^{17}$ En el caso colombiano,

\footnotetext{
${ }^{13}$ Manzanilla, "Los guardacostas de Cartagena de Indias...", 84-88.

${ }^{14}$ Malagón, "El consulado de comercio de Cartagena", 54.

${ }^{15}$ Sergio Paolo Solano de las Aguas, "El Apostadero de la Marina de Cartagena de Indias, sus trabajadores y la crisis política de la Independencia", Economía y región 9, n. 1 (2015): 212.

${ }^{16}$ Malagón, "El consulado de comercio de Cartagena", 55.

${ }^{17}$ El trabajo que presentan profesor y estudiante se compone de la unión de resultados de estudios individuales. Fernando Jumar e Isabel Paredes, "El comercio intrarregional en el complejo
} 
TEMPUS. Revista en Historia General Medellín (Colombia), 2018, septiembre-octubre, número 8

ISSN: 2422-2976

un país con menor tradición naval, el Caribe y el Pacífico han sido objeto de estudio de laboriosos intelectuales lugareños y uno que otro connacional desde varios campos de la historia. Pero, en cuanto a los comisos, en general se ha abordado la materia desde el campo del derecho y la jurisprudencia; en donde se realizaron avances para la contextualización histórica del procedimiento judicial como tal. ${ }^{18}$ La obra del profesor Treviño describe el accionar de los corsarios en Santo Domingo y los pormenores de los juicios de mercaderías y embarcaciones, los que se conocían como juicios de comiso; en esto coincide con el trabajo de Jumar y Paredes, quienes describen la estructura del juicio para formar un estudio económico del comiso, como un renglón de entrada en las cajas reales. La comparación de los resultados finales de los estudios individuales en Jumar y Paredes dio paso al deseo de profundizar de manera conjunta en los documentos para indagar por las implicaciones sociales de la institución de comisos en las Indias. De ahí resulta el texto en cuestión, un avance en dicha temática, aunque sus planteamientos no logren alejarse demasiado de los presentados en el trabajo del profesor Manuel Alberto Restrepo Medina.

Nuestro objetivo principal es recurrir a la documentación existente en torno a los comisos buscando aprovechar los aspectos de tipo social, que han quedado como sepultados bajo las losas frías y pesadas de la jurisprudencia y la economía. ${ }^{19} \mathrm{Al}$ tiempo que, los historiadores han prestado más atención a aspectos relacionados con la problemática, como el tráfico de esclavos africanos o el contrabando en general de mercancías, sin advertir en las posibilidades para la historia social de tales documentos. Similares a los de cualquiera de tipo judicial, pues revelan en detalle la identidad de los implicados y la realidad en la que se desenvolvían. De esta manera queremos prefigurar el desarrollo del nuevo patrón de comercio en las Indias y el accionar de aquellos portuario rioplatense: el contrabando visto a través de los comisos. 1693-1777", América Latina en la historia económica, n. 29 (2008): 33-98.

${ }^{18}$ Se trata de los resultados presentados por el director de la Línea de Investigación Tendencias y perspectivas del derecho administrativo de la Universidad del Rosario: Manuel Alberto Restrepo Medina, El comiso: análisis sistemático e instrumentación cautelar (Bogotá: Editorial Universidad del Rosario, 2007), 25.

${ }^{19}$ Nuestro primer acercamiento al asunto de los comisos se dio a raíz del expediente formado por unas balandras francesas encontradas en aguas del río Orinoco en 1766. "Caminos de agua, ciudades itinerantes y capillas portátiles: poblamiento en el río Orinoco a través del siglo XVIII", (Tesis de pregrado, Universidad de Antioquia, 2017), 80. 
que intervenían en él, precisamente a portas del establecimiento del capitalismo económico. ${ }^{20}$ Nuestras fuentes reposan especialmente, en los Archivos General en Bogotá y General de la Marina. Hemos accedido a los documentos de este valioso repositorio gracias a la Biblioteca Virtual del Ministerio de Defensa español. El avance en otros campos de la investigación sin duda posibilitara tal cometido, como lo viene haciendo hasta ahora; uno que busca contribuir a la integración historiográfica e intelectual.

\section{El norte de Suramérica y el Atlántico como teatro de operaciones}

Con Felipe V tratando de alcanzar estabilidad aparece un testimonio temprano de comiso, que puede ilustrar la situación del contrabando en la época y que, significativamente no implica a súbditos de coronas extranjeras, sino a españoles; incluso allegados al nuevo monarca. Además, este ocurre en el interior del virreinato y no en las costas. A principios del siglo XVIII existía en la capital Santafé un consulado en el que los comerciantes del interior se agremiaban para defender sus intereses y controlar el desarrollo del mercado local, mientras conservaran el favor de la corona ${ }^{21}$. El 3 de febrero de 1708, el administrador del Real derecho de alcabala Bartolomé Gómez de Abreu se presentó ante la cúpula del consulado -prior y cónsules- llevando consigo una carga de fardos que declaró haberse introducido de forma irregular en la ciudad. De acuerdo con el apresador fue avisado el día anterior "por una persona secreta" de la falta cometida el 1 de febrero y enseguida supo que eran "dos cargas de fardos una grande y otra pequeña y haziendo la diligensia tuvo noticia estavan en casa de pedro ortis". Al instante acudió a tal lugar, donde solo encontró a la mujer del señalado. Después de registrar la casa encontró la carga "en un aposento bajo dos fardos". La mujer cuando fue requerida dijo luego, "al declarante que su marido le avia remitido dichos fardos con unos indios segun se lo dijeron y que no avian traido mas cargas y que no supo si traian despachos o que solo le dijeron los indios que su marido lo remitia y que los [tubiese] hasta que viniese [...]”. El consulado mandó a que, tanto aprehensor como

\footnotetext{
${ }^{20}$ Xavier Lamíkiz, "Patrones de comercio y flujo de información comercial entre España y América durante el siglo XVIII", Revista de historia económica, n. 2 (2007): 237.

${ }^{21}$ Anthony McFarlane, "Comerciantes y monopolio en la Nueva Granada. El consulado de Cartagena de Indias", Anuario colombiano de historia social y de la cultura, n. 11 (1983): 60.
} 
TEMPUS. Revista en Historia General Medellín (Colombia), 2018, septiembre-octubre, número 8

ISSN: 2422-2976

aludida presentaran sus declaraciones ante el escribano de la ciudad "y se hagan las mas diligencias que combengan asi para [descubrir] la otra carga de Ropa como para aberiguar la verdad"; lo que se cumplió inmediatamente.

El apresador sostenía que, el esposo era culpable por haber sin registro "entrado en esta ciudad a media noche dos cargas de fardos de Ropas de castilla", después de esto fue que el señalado los había remitido con unos indios a su mujer; en tal falta resaltaba el agravante de realizar sus acciones "de noche contra lo mandado". La mujer se mantuvo en que "antenoche como poco despues [de] las orasiones" los indios arrieros de su marido habían traído las cargas, lo único que decía saber de más es que fletaría "unas mulas para traer unas cargas de arros", de un tal Pedro Baca que vivía "en casa del maestre de campo don Agustin de londoño [el] qual fue a rezevir dichas cargas y las trajo a dicha casa del dicho maestre de campo y de alli [...] Remitieron con dichos yndios los dos fardos y que no save otra cosa y que es la verdad so cargo de juramento fecho y no firmo por no saver."22 El capitán Lorenzo de Alea y Estrada se apersonó del caso y luego de excusar al carguero dijo que este no portaba las licencias y certificados por que "el dicho pedro ortis se atraso en el camino y la adelanto con sus harrieros". Pidió que se le devolviera la carga decomisada para lo que presentó pruebas de haber pagado derechos y levantado los registros (guías y despachos) correspondientes en el puerto de Cartagena de Indias y en el de Honda; escala fluvial de Santafé sobre el río Magdalena. Ante la aparente veracidad de la guía del comisionado en Honda y el despacho de la carga desde Cartagena de Indias, los diputados del consulado refutaron que ese no era el único requisito y añadieron que, para que las cargas pudieran entrar de manera legal debían "entrar de Dia y manifestarse a las Guardias del Comersio y Administrador de Alcavala [y] estos pasar a hazer Rejistro de ellas al Consulado o a sus Diputados, para que puedan o no dar el Passe, y con esto no se Reconozerá fraude assi al Comersio, como a la Real hazienda".

\footnotetext{
${ }^{22}$ Es posible que esta casa a la que se refiere sea la misma conocida como del marqués de San Jorge, la cual alberga en el siglo XXI un museo arqueológico y está hoy ubicada en "la calle del Fiscal" (carrera 6, calle 7-43) en Bogotá D.C.; Diana Cristina Villada Cardozo, "Objetos convertidos en conceptos: la apropiación del patrimonio arqueológico en el municipio de Nemocón", (Tesis de maestría, Universidad Nacional de Colombia, 2011), 16.; "El marqués reabre su casa", El Tiempo (Colombia), 28 de julio de 1995, 1.
} 
De acuerdo con el expediente se sabía que el arribo de las cargas a Cartagena de Indias se dio en el navío Nuestra Señora de la Concepcion Señor San Joseph y San Francisco Xavier, a cargo del maestre don Juan de Espeleta, que navegaba bajo el patronaje "del General Conde de Cassaalegre" y figuraba en el puerto el 1 de mayo de 1706. Allí se hizo avalúo de los géneros, junto con los de los demás galeones, supuestamente compensando los derechos correspondientes. ${ }^{23}$ Pero en ultimas, el peso de la justicia recayó sobre el acusado en Santafé, a quien se le advirtió que en adelante no entrara de noche fardos en la ciudad o "se le benderan las mulas declarándolas como se declaran por decomiso" 24 . Parece que no se rastreó a profundidad el paradero del resto de la carga, que había sido establecida en 5 fardos en Cartagena de Indias, ni se sometió a cuestionario a ningún otro de los implicados, funcionarios o no. Dejando así de atacar las causas estructurales del contrabando, que podían llegar a involucrar a las máximas autoridades de la flota de Indias -como hemos visto-, la corona española optó por reforzar sus sistemas de control y vigilancia. Medidas más de forma, razón por la cual en 1710 se dio orden para que las mercancías se pesaran y luego se les hiciera “[cerrar] las costuras sellándolas”, para esto se utilizaría un sello oficial en lacre. Así se hizo, por ejemplo, en agosto de 1710; con "dos cargas de mercaderias y media de merseria". Que fueron detenidas por orden del Consulado de Santafé y luego de pesarse una de ellas "se lacreo con dies lacreaduras de lacre colorado, para las corduras y sobre dichas lacreaduras se le ymprimio [sello] por las Armas". 25

Es esta la base sobre la que se articuló el sistema de comercio borbónico. La noticia de arribadas maliciosas y aprehensiones se antepuso al establecimiento de la red de Apostaderos que se extendió a lo largo de las Indias. ${ }^{26}$ Entre los primeros eventos costeros que registramos hay uno que curiosamente tiene lugar en el puerto de Concepción, en Chile, como testimonio quizá de la paridad de las dificultades en la primera mitad del siglo XVIII; desde el Atlántico al Mar del Sur. En aquel puerto, el

\footnotetext{
${ }^{23}$ Lamíkiz, "Patrones de comercio y flujo de información comercial...," 239. https://web.archive.org/web/20060211002733/http://es.geocities.com/santillan1708/ \# Toc102050541 (consultada el 11 de febrero de 2018).

${ }^{24}$ AGN, Miscelánea, t. 112, doc, 16. ff, 110r-116r.

${ }^{25}$ AGN, Miscelánea, t. 71, doc, 85. ff, 725r.

${ }^{26}$ Manzanilla, "Los guardacostas de Cartagena de Indias...”, 291-293.
} 
TEMPUS. Revista en Historia General Medellín (Colombia), 2018, septiembre-octubre, número 8

ISSN: 2422-2976

navío Trinidad fue aprehendido el 19 de diciembre de 1743, algo de lo que se daba aviso a las autoridades de "Guaiaquil, y demas parages de su Governacion" con relación a lo que había de practicarse en el tema, según la experiencia de lo ocurrido en Chile. Asimismo, se libraba "igual despacho al señor Virrey del Perú", al que se le notificó dirigiéndole una ejecutoria del pleito seguido, que parece haber estado resuelto apenas para 22 de mayo de 1753; documento que terminó luego en los archivos del Virreinato del Nuevo Reino de Granada. ${ }^{27}$ En Cartagena de Indias las aprehensiones ya habían tenido lugar para 1763, luego de escaramuzas y seguimientos el jabeque del rey llamado el Galgo apresó a dos balandras inglesas que se encontraron fondeadas cerca de las costas de Cartagena de Indias y La Guajira, bajo el pretexto de estar practicando la pesca de tortuga ${ }^{28}$. Los navíos fueron llevados al puerto de Cartagena de Indias y las tripulaciones puestas en prisión. A la postre el gobernador de Jamaica, Littleton comisionó al contralmirante Keppel, comandante en jefe de la armada inglesa en aquella isla; para que pasara a Cartagena de Indias "a reclamar esta Balandra, y otra que se nombra el Gryhound". ${ }^{29}$ De esta manera se presentó a bordo del Richmond, un navío de guerra "al Ancla en el placer de Vocachica", con requerimientos del gobernador de Jamaica y de los dueños de las balandras detenidas.

El comandante transmitió a las autoridades de Cartagena de Indias la petición para que fueran devueltas inmediatamente. Apelaba al supuesto derecho de pesca consagrado en los tratados entre los dos monarcas, católico y protestante. Aunque para los españoles no existía tal cosa en ningún tratado, pero en vista de la situación se permitió la liberación de los capitanes y su regresó a Jamaica "dando fiansas para las resultas de la determinacion de S.M.C”. Entonces, las posteriores pesquisas a nivel virreinal y metropolitano apoyaron el comiso de los efectos, por lo que los fiadores tuvieron que asumir los costos en 1764. Terminada la Guerra de los Siete Años y con las colonias

\footnotetext{
${ }^{27}$ AGN, Miscelánea, t. 92, doc, 7. ff, 263r.

${ }^{28}$ El jabeque aparece como el descendiente directo de la antigua galera, esta suerte de eslabón de la evolución técnica le valía ser alabado por unos y por otros vilipendiado. Al juzgar que tenía poca capacidad para operar en el Caribe, por ser una embarcación de origen mediterráneo. http://www.cuervas-mons.com/spanish\%20jabeque.htm (Consultada el 12 de marzo de 2018).

${ }^{29}$ Vale la pena anotar que el vocablo greyhound se traduce al español como galgo. AGN, Milicias y Marina, t. 33, doc, 8. ff, 622r-654r.
} 
españolas seriamente dañadas por las hostilidades inglesas, la reconstrucción de las defensas era imperante para Carlos III. Aunque, con la llegada de Julián de Arriaga a la secretaría de Marina el crecimiento de la armada se estancaría por años. Otra vez España veía menguado su poder naval, en especial por el género de victoria pírrica de Juan José Navarro, que formó la escuadra franco-española en Tolón en 1744 y por la posterior destrucción de 6 buques de guerra en La Habana en $1748 .{ }^{30}$ En lo adelante, los informes de costos y las relaciones de personal de las plazas amenazadas en el Caribe se repetirían hasta finales del siglo XVIII, algo de lo que Portobelo es ejemplo. ${ }^{31}$ A partir de entonces España seguiría en desventaja pues, no más al poner fin al conflicto fue contabilizada en la región de Bacalar (actual Estado mexicano de Quintana Roo) en 1765 una flota inglesa compuesta por, "81 fragatas, 40 bergantinas, 20 balandras, 50 goletas y bongos con una capacidad que iba desde las 10 hasta las 36 toneladas cada una". 32

En medio de todo, durante el reinado de Carlos III la buena situación de gobierno y el crecimiento económico permitirían un despunte del índice de poder naval, "la época dorada de la Marina española" que iba a alcanzar el mayor número de unidades al comienzo del reinado de Carlos IV; con antelación a los desastres del cabo de San Vicente en 1797 y Trafalgar en $1805 .{ }^{33}$ Es entonces cuando logra mayor difusión el "comercio de balandra", del tipo descrito por Antonio García de León. ${ }^{34}$ Pues, aunque los llamados "registros sueltos" representaban entre 1550 y 1650 , cerca del $20 \%$ del total de embarcaciones que cruzaron el Atlántico con licencia española. ${ }^{35}$ Para el periodo de 1739-1778 casi el 80\% del total del comercio colonial de España se hizo mediante las embarcaciones menores, por lo que de paso el sistema de guardacostas se

\footnotetext{
${ }^{30}$ El título de Real Armada quedó en firme tras las reformas de José Patiño, quien unificó las distintas fuerzas navales del imperio español. Pradells 48-54.

${ }^{31}$ AGN, Miscelánea, t. 113, doc, 13. ff, 115r.

${ }^{32}$ Alicia del C. Contreras Sánchez, "El palo de tinte, motivo de un conflicto entre dos naciones, 1670-1802", Historia mexicana 37.1 (1987): 67-68.

${ }^{33}$ Pradells, "La formación de la Marina española en el siglo XVIII", 45-46.

${ }^{34}$ García de León, "Comercio de balandra, contrabando y piratería en el Golfo de México", 181.

${ }^{35}$ Milton Zambrano" "Piratas, piratería y comercio ilícito en el Caribe: la visión del otro (15501650)”. Historia Caribe n.12 (2007): 27.
} 
TEMPUS. Revista en Historia General Medellín (Colombia), 2018, septiembre-octubre, número 8

ISSN: 2422-2976

volvió indispensable. ${ }^{36}$ La libertad de comercio sería decretada en 1778, pero su aplicación puntual en las colonias hispánicas solo fue posible luego del desenlace de la Independencia de los Estados Unidos en 1783 algo que, en ultimas vendría apenas a validar la situación del momento; pero aumentando de paso el número de embarcaciones que recibían los puertos ${ }^{37}$. Para la década de 1770 España, a pesar de todo, se sentía tan fortalecida como para avanzar en su estrategia de detrimento al contrabando. Así, el 5 de noviembre de 1770, la balandra Divina Pastora estando fondeada en la bahía de Riohacha avistó "a cosa de las onze y media de la mañana”, una balandra que hizo tránsito y luego atracó, "la que se reconocio por su vandera ser de nacion francesa" ${ }^{38}$. El teniente de fragata don Baltasar de Echavarri, al mando de la Pastora dio instrucciones para que el capitán francés pasara a bordo del guardacostas y llevase consigo todas sus credenciales "como son la Licencia, Pasaportes diario de navegacion, Rol de [su] gente, Cartas de Conocimiento, factura de Cargamento que acreditasen la consistencia de su Buque", lo que se cumplió en presencia de testigos.

Acto seguido el capitán francés había huido y desaparecido, "por cuio motivo no consta su declaracion". Interrogados los marineros, ellos dijeron que la carga de "Arina, Aguardiente, queso, frasqueras, Losa, Cera, Machetes, y sables" fue embarcada en Curazao y que toda era del capitán. Por último, se interrogó a un particular que encontraron como pasajero en la nave apresada, el cual dijo llamarse don Bernardo de Silva y asimismo ser "natural de Amsterdam de la Republica de Olanda de hedad de veinte y nueve años"; este confirmó en pleno la versión entregada por los tripulantes. Cumplida la diligencia, el capitán guardacostas "hallando merito suficiente" hizo que don Vicente de Castro y Cubillas, maestre y contador de la balandra guardacostas pa-

\footnotetext{
${ }^{36}$ Lamíkiz, "Patrones de comercio y flujo de información comercial...", 237.

${ }^{37}$ Anthony McFarlane, "El comercio exterior del virreinato de la Nueva Granada: conflictos en la política económica de los borbones", Anuario colombiano de historia social y de la cultura 6, n. 7 (1972): 69.

${ }^{38}$ El contrabando de los franceses había tenido que ser tolerado tras su colaboración en la Guerra de Sucesión, por lo que se encontraba bastante difundido. Carlos Newland, "Globalización en el imperio español: precios y comercio entre 1661 y 1810", XXII Congreso Internacional de Latin American Studies Association, Hyatt Regency-Miami, 16-18 de marzo de 2000, 5; Muriel Laurent, "Nueva Francia y Nueva Granada frente al contrabando: reflexiones sobre el comercio ilícito en el contexto colonial", Historia critica, n. 25 (2003): 139.
} 
sara "a bordo a clavar las Escotillas, despues de Reconocer lo que se pudiese, por no haver tiempo para el fondeo formal". El maestre contador hizo lo propio y pasó a la balandra apresada, que resultó se nombraba el Recurso y además tenía como alias la Palomino. ${ }^{39}$ Guardacostas y presa se dirigieron a la bahía de Cartagena de Indias, donde el gobernador y su gabinete reunidos en la Real Contaduría decretaron los procedimientos reglamentarios, como la puesta en almoneda de una parte de la carga "por ser muchos de los generos de inmediata corrupcion, de derrames, y desperdicios"; al igual que visitas sanitarias e inventarios, "interin se formalisen las previas diligencias a preparar, y conocer de la naturaleza de esta causa, mediante al Pasaporte, con que navegó la referida Balandra". El capitán fugitivo que, por la factura se supo era Juan Gazan reapareció en Santafé donde pidió la intervención del virrey en el asunto. Sostuvo que su tránsito era legítimo y que los géneros consumibles estaban destinados a socorrer a la ciudad de Riohacha, por entonces sitiada por la revolución de los indios guajiros. Por su parte, cualquier otra mercancía que estuviera bajo sospecha, como las que se hallaron tras la inspección en el sitio de almacenaje, según Gazan seguramente haría parte de una encomienda que se le hizo en Curazao, donde acudió en su plan de socorro a Riohacha.

Por la traducción que hizo don Antonio de Narváez y de la Torre, de los documentos originales en idioma francés se anotó que las mercancías figuraban bajo el nombre de "nos Iden, Schotborg, Van starkenborg, vecinos, y comerciantes en la ysla de Curacao", quienes certificaban haber embarcado en la balandra Resource de Gazan "catorze Barricas, con mercadurias, secas". El cargamento era remitido "Todo a la consignacion de los señores, Marion Budan, y Compañia comerciantes en Porto au Prince, de la Ysla de santo Domingo Francez", a los cuales se les había dado aviso anteriormente según ellos, con el capitán Juan Blanco; con el que "trasladamos el vando de nuestro copiador de cartas". En su defensa Gazan expuso que, justamente, la premura por socorrer Riohacha y la de evitar acciones hechas por corsarios lo llevaron

\footnotetext{
${ }^{39}$ Los problemas de doble registro son recurrentes y una práctica habitual de algunas embarcaciones. Otras variantes de este fenómeno consistían en llevar pabellón falso o cambiarlo según fuese menester, lo que implicaba tener diferentes a bordo.
} 
TEMPUS. Revista en Historia General Medellín (Colombia), 2018, septiembre-octubre, número 8

ISSN: 2422-2976

a virar sin entregar el flete. Refugiado en la corte del virrey y remiso a asistir a Cartagena de Indias, donde se le instaba a comparecer prefirió dar poder al procurador del número Mathias Carracedo. Mientras tanto en Cartagena de Indias, el 28 de noviembre de 1770, el gobernador don Gregorio de Sierra, el comandante del guardacostas don Martin de Lastarria, junto con "Don Raphael de Escovar, Thesorero, y Don pedro Montero, Contador; Oficiales de la Real Hacienda”. Se encontraban reunidos según el expediente, "como se acostumbra en esta sala de Audiencia del Real Contaduria"; decidían el futuro de la balandra el Recurso. Pues apremiaba otro asunto, al parecer desde España, don Julián de Arriaga ordenó "reservadamente al capitan de fragata Don Juan de Lombardon, comandante del comboy que se halla desembarcando, que al paso de las costas de Caracas, destacase de dicho comboy el Buque, que le avisase en cadiz, el señor yntendente, Don Juan Gerbout, en que se transportavan los generos consignados al Puerto de la Guayra". Su objetivo era remitir a Caracas "a la saetia San Jayme, en que se transportavan ochocientos quintales de polvora, tres mil fuciles, cien mil piedras de chispa, mil caltucheras, y tres Turquesas modelos de valas y tamvien le reencargó que esta especie, no transcendiese al publico".

El problema radicaba en que el capitán Lombardon decidió ya en altamar llamar “a la saetia su capitan Don Jayme Guall. una de las dos de [un] propio nombre que han navegado en su Comboy, porque ay otra San Jayme, y con solo la diferencia, en la del Capitan que lo es Francisco Milans", por lo que no se cumplió el objetivo. En consecuencia, el gobernador de Caracas solicitaba tiempo después, que se "procure remitirselos a Puerto Cavello quanto mas antes por Faltar, en aquella Provincia armamento y municiones". Por lo que, la Junta en Cartagena de Indias propuso "que hallandose retenida la Balandra nombrada la Palomino, o el Recurso, su capitan Juan Gazan, que decertó [...], granvelera, y de [diligencia] segun se esperimento desde el Hacha, a este Puerto", lo mejor era que; "en atencion de hallarse havilitada la Balandra Nepomuceno, y en iguales circunstancias la Retenida Palomino, osea el Recurso [...] ambas se equipen como para transporte, y se carguen en ellas todo el armamento, polvora y municion”. El plan se llevó sin reveses, por lo que se cumplió con el inventario realizado por los oficiales reales en el puerto de La Guaira, "Don Manuel de Salas, thesorero, y 
Don Juan Vizente Bolivar, contador". 40 A su regreso la embarcación apresada fue asignada definitivamente al guardacostas de Cartagena de Indias. ${ }^{41}$

Para entonces, el hombre fuerte en la Real Aduana de Cartagena de Indias se llamaba Ignacio Cavero. El rey Carlos III había ensayado en Nápoles la recaudación fiscal mediante una Aduana que controlara el comercio. En búsqueda de una unidad arancelaria y a causa de la creciente cantidad de competencias aduaneras, se terminó en 1769 una sede oficial para la Real Aduana de Madrid, (actual sede del Ministerio de Hacienda español) ${ }^{42}$. Por lo que la fecha exacta del establecimiento de la Real Aduana en Cartagena de Indias fue tiempo después, en la sede de la antigua Real Contaduría y la plaza que hoy lleva ese nombre. Algo es seguro, Cavero que era yucateco y había llegado al virreinato con el arzobispo Caballero y Góngora fue nombrado presidente de la Junta Gubernativa de Cartagena de Indias y figura firmante de la declaración de Independencia. Inclusive el arzobispo, como virrey llegó a ubicar un tiempo su casa en la localidad de Turbaco, "residencia habitual de la plutocracia mercantil cartagenera, a unos veinte kilómetros de la ciudad" ${ }^{43}$ Territorio polémico, por el que se acusaba al Consulado de Cartagena de Indias de haber desviado recursos a la construcción de un camino, "cuya única utilidad, era conectar las casas de los comerciantes ricos de Cartagena con sus haciendas y fincas de recreo en el balneario". ${ }^{44}$ De esta manera se había dejado de adelantar el mantenimiento de caminos que conectaban el Caribe con el interior, al igual que de la navegación del rio Magdalena y el canal que lo conecta con la bahía del puerto colonial.

\footnotetext{
${ }^{40}$ Don Juan Vicente Bolívar, que mediaba la centuria iba a contraer matrimonio en 1773 con doña María de la Concepción Palacios y Blanco, quinceañera. El 24 de julio de 1783 nació en Caracas su tercer hijo, Simón Bolívar. Camilo Calderón Schrader, "Un niño llamado Simón. La infancia difícil del forjador de la Libertad", Credencial historia, n. 144 (2001): http:// www.banrepcultural.org/biblioteca-virtual/credencial-historia/numero-144 (consultada el 24 de marzo de 2018).

${ }^{41}$ AGN, Negocios exteriores, t. 6, doc, 13. ff, 380r-499v.

${ }^{42}$ Francisca Bernabé Montalbán, "La Real Casa de la Aduana de Madrid", (Trabajo final de ciclo-Universitat per a Majors, Universitat Jaume I, 2009), 13.

43 http://pacarinadelsur.com/home/figuras-e-ideas/1391-cavero-y-melo-dos-bolivaristas-en-lavida-de-mexico. (consultada el 11 de marzo de 2018).

${ }^{44}$ McFarlane, "El comercio exterior del virreinato...", 70.

${ }^{45}$ McFarlane, "Comerciantes y monopolio...," 66.
} 
TEMPUS. Revista en Historia General Medellín (Colombia), 2018, septiembre-octubre, número 8

ISSN: 2422-2976

Junto a estos elementos, la promoción del arzobispo-virrey del comercio con los países neutrales como los Estados Unidos o Dinamarca, para proveer harina más barata que la producida en los Andes orientales; fue motivo para el deterioro de las relaciones con el interior del virreinato, el mismo que se iba a manifestar durante los primeros momentos de independencia. ${ }^{46}$ Pero, Ignacio Cavero no solo es relevante por su peso en la Real Aduana o su posterior presidencia en la Junta de Gobierno. El yucateco, prócer de la independencia, también estaba casado con María Teresa de Leguina, sobrina de Juan Elías López Tagle y familiar de José María García Toledo, igualmente próceres y mártires. Más aún, Josefa de Leguina, hermana media de su esposa estaba casada con José Antonio Amador, miembro de una de las más poderosas familias de comerciantes de origen gaditano radicada en Cartagena de Indias. Un hermano de este último era Sebastián José Amador López, quien fue gobernador de Antioquia en 1851, padre del empresario antioqueño Carlos Coroliano Amador en $1835 .{ }^{47}$ Para terminar, Teresa, la hija de Ignacio Cavero sería la segunda esposa de Juan José Nieto Gil; hijo de un "curandero, partero y albañil, quien además fabricaba mechas de algodón". Nieto Gil es considerado el primer presidente afrodescendiente de Colombia. ${ }^{48}$ En cuanto a las embarcaciones de bandera neerlandesa, es preciso decir que durante las últimas décadas del siglo XVIII estas se dedicaron a efectuar operaciones de contrabando desde sus colonias en Curazao, Aruba o Bonaire, en una operación que se dirigió a territorios como las costas de la Capitanía General de Venezuela e islas del Caribe como Saint Thomas; cuando la colonia danesa empezó a recibir barcos extranjeros con provisiones, ante la incapacidad de Dinamarca para comerciar con su capital Charlotte Amalie. ${ }^{49}$ Sin embargo, en ocasiones merodeaban por La Guajira, donde aspiraban una participación de los metales preciosos virreinales, tan escasos en otros territorios ${ }^{50}$

\footnotetext{
${ }^{46}$ Franco, "En pos de los intereses comunes", 109-110.

47 http://enciclopedia.banrepcultural.org/index.php/Carlos_Coroliano_Amador_Fern\% $\% 3 \%$ A1ndez. (consultada el 15 de marzo de 2018); Adolfo Meisel Roca, "Entre Cádiz y Cartagena de Indias: La red familiar de los Amador, del comercio a la lucha por la independencia americana", Cuadernos de historia económica y empresarial, n. 12 (2004): 17-20.

48 Javier Ortiz Cassiani, "La memoria difusa de un presidente negro", El Espectador (Colombia), 24 de enero de 2009, 1.

${ }^{49}$ Vergara, "Los vínculos entre la provincia de Caracas y la isla caribeña de San Thomas...", 173.

${ }^{50}$ Manzanilla, “Los guardacostas de Cartagena de Indias...," 157.
} 
Regularmente, los holandeses llegaban a Riohacha, pero también asomaban por otros parajes como Bahía Honda o Bahía Portete, más al norte; llegaban "a comerciar perlas, cacao, mulas, palo de tinte, cueros y algodón". ${ }^{51}$ La naturaleza geográfica de la península -bastante proyectada en profundidad hacia el Caribe- vino a ser propicia para el trato ilícito, no solo por la dificultad de conectar por vía terrestre, sino marítima, al imperar un régimen de vientos que tornaba bastante complicado el que los barcos cumplieran el trayecto desde Cartagena de Indias y Santa Marta. Por lo que, La Guajira llegó a convertirse en punto clave para el contrabando, en el que nativos de la zona llegaron a articular incluso, una red de circulación de mercancías hacia el interior del virreinato; en conjunto con las poblaciones de sitios como Mompox y Valledupar. Además, durante el siglo XVIII buena parte de las costosas expediciones española que se organizaron para someter a los guajiros resultaron infructuosas. ${ }^{52} \mathrm{Al}$ rededor de 1770, luego de haberse dispuesto un plan para poblar la península de La Guajira de manera controlada tuvo que ser necesario contratar con los comerciantes de Curazao el suministro de mercaderías para el fomento de los nuevos sitios. Pero al parecer, los neerlandeses no tardaron en exceder los términos del contrato con España. ${ }^{53}$

Aunque era Inglaterra quien comenzaba a dominar en los mares. $\mathrm{Y}$ los buques mercantes ingleses no se desgataban para entonces en rodeos, menos en vísperas de la gran consagración británica en 1805 en Trafalgar. ${ }^{54}$ De esta forma, don Cosme de Carranza, el 21 de julio de 1801 informaba sobre estarse divulgado la noticia de haber llegado a las costas inmediatas a Santa Marta "un comboy de once Buques procedentes de Jamayca con crecidos intereses en Ropas, escoltados por una Fragata de 40 cañones y dos Bergantines de 18 y 14". La fragata no efectuó ningún tipo de hostilidades en ese

\footnotetext{
${ }^{51}$ Ruth Esther Gutiérrez Meza, "Orden, poder y contrabando en el Caribe durante el medio siglo antes de la independencia", Palobra, n. 12 (2010): 198.

${ }^{52}$ Leonardo Guillermo Moreno Álvarez, "La piratería americana y su incidencia en el Nuevo Reino de Granada, siglos XVI-XVIII: un ensayo bibliográfico", Fronteras de la historia, n. 12 (2013): 392.

${ }^{53}$ Manuel Gámez Casado, "La pacificación de La Guajira por el ingeniero Antonio de Arévalo. Sobre el proyecto de defensa de Sabana del Valle", Laboratorio de arte, n. 28 (2016): 375; AGN, Poblaciones, t. 10, doc, 139. ff, 853r-855r.

${ }^{54}$ Enrique Zafra Caramé, "Horatio Nelson versus Blas de Lezo", Revista general de marina 267, n. 3 (2014): 477.
} 
TEMPUS. Revista en Historia General Medellín (Colombia), 2018, septiembre-octubre, número 8

ISSN: 2422-2976

momento, pero decía Carranza que "permanecio detenida a distancia de dos Leguas de la Ciudad por espacio de dos oras, y le noté hizo señales con Banderas por dos ocasiones". Al final sentenciaba en tono aliviado como, "al ponerse el sol continuó alejandose mar a fuera con pocas velas y la briza venteaba fresca" $"$. Cosme de Carranza y Vivero era considerado en Cartagena de Indias, incluso por el hermético Consulado, como "persona íntegra, celosa de su trabajo e inteligente". ${ }^{56}$ Los comerciantes del gremio cartagenero optaron por zanjar las disputas perennes en relación con la conveniencia de articular el ejercicio de guardacostas con oficiales del rey o con armadores particulares. Sobre todo, cuando estas limitaron el control efectivo de la jurisdicción, una situación que se tornó critica desde finales del siglo XVIII; con el inicio de las llamadas Guerras Navales (1796-1808), entre Inglaterra, Francia y España. ${ }^{57}$ El presupuesto del Apostadero aumentó, pero buena parte de los recursos debían destinarse para pagar a los acreedores. ${ }^{58}$ La resolución oportuna de los juicios de comisos, que representaban un ingreso primordial para el sostenimiento de la escuadra guardacostas, ya desde 1787 estaba sufriendo de una grave demora, como muestra la evidencia que existe. ${ }^{59}$ Esta situación reducía la posibilidad de percibir montos elevados por las presas, lo que significaba claramente dificultades en el ejercicio del resguardo naval. ${ }^{60}$

\section{Las guerras navales y la independencia}

Incluso, Carranza comenzó a tener problemas con el gobernador Cejudo, que se quejó de él ante el virrey, según decía "por haver puesto un Guardacosta en Bocachica para reconocer todos los Buques que entran al puerto". ${ }^{61}$ Para 1788, los comisos estaban extendidos en tierra, pero al parecer no a manera de fortalecimiento de aquellos que; en tiempos de la Guerra de Sucesión alcanzaban a poner en un posible expediente

\footnotetext{
${ }^{55}$ Archivo General de Marina "Don Álvaro de Bazán” (España), Expediciones a Indias, c. 28, doc, 79. ff 1r-2r. En adelante (AGM).

${ }_{56}^{56}$ Manzanilla, "Los guardacostas de Cartagena de Indias...", 182-183.

${ }^{57}$ Rodríguez Treviño, "La red del corsario francés Juan Chevallier", 116.

${ }^{58}$ Solano de las Aguas, "El Apostadero de la Marina de Cartagena de Indias", 216-217.

${ }^{59}$ Fue necesario acudir a pedir tripulantes en poblaciones como Soledad. AGN, Milicias y Marina, t. 68, doc, 42. ff, 276r-276v.

${ }^{60} \mathrm{AGN}$, Miscelánea, t. 123, doc, 16. ff, 210.

${ }^{61}$ AGN, Aduanas, t. 13, doc, 41. ff, 624r.
} 
por contrabando, el nombre de prestantes súbditos de la corona española. Más bien, al estar cerca el gobierno borbón de cumplir una centuria y sin poder erradicar la contravención de sus colonias, menos todavía los asentamientos de otras naciones europeas; las acciones para perseguir las mercancías ilegales estaban enfocadas en los propios habitantes de las colonias españolas. Cualquiera podía ser un potencial transgresor entonces y de esa forma se le perseguía. En Maracaibo fue detenido "Fr. Ygnacio Albarez, del orden de San Francisco", al que se acusó por los elementos de su equipaje, "en atencion a conducirlos sin guia y a ser algunos de ellos extrangeros". ${ }^{62}$ En Cartagena de Indias, en tiempos del gobernador Antonio Cejudo, año 1800 "en virtud de denuncio"; don Joaquín Lores "El theniente de Guarda mayor del resguardo de esta plaza", luego de llegar a una casa "del Barrio de Gimani” aprehendió en uno de los cuartos “12, piezas de zarasa: una de Machon y 16, Dozenas de pañuelos de Morzolina”. Se trataba de un comiso menor, a menos que la almoneda haya estado poco frecuentada, al tener en cuenta que se subastaban textiles importados; pues como se anotó quedó "en doscientos once pesos seis y tres quartillos reales y se quedan practicando las diligencias relativas a su venta, y a la prixion de la que havitaba el quarto que hizo fuga" ${ }^{63}$ Tal situación podría explicarse por la dinámica de las acciones de comiso, que se enfocaban de acuerdo con los intereses de los agentes aprehensores, como se denominan en el trabajo de Jumar y Paredes; que perseguían según el caso a los grandes contrabandistas o a aquellos dedicados al contrabando hormiga ${ }^{64}$

Es factible, en especial teniendo en cuenta el contexto de necesidad expansiva de una base contribuyente. De igual manera, otra causa puede remitirse a un direccionamiento adrede y progresivo de la justicia hacia los sectores más pobres, tal como lo plantea Nectalí Ariza, en su estudio sobre la vida privada en Cartagena de Indias desde mediados del siglo XVIII. Según él, "En los documentos de la época se menciona que, la burocracia, las fuerzas militares, el clero, los comerciantes y los pobres, participaban del contrabando. Estos últimos, eran los más perseguidos, algo necesario para

\footnotetext{
${ }^{62}$ La sentencia fue aprobada por el rey de España en Madrid el 12 de diciembre de 1792. AGN, Miscelánea, t. 82, doc, 27. ff, 141r-141v.

${ }^{63} \mathrm{AGN}$, Miscelánea, t. 112, doc, 87. ff, 839r-840r.

${ }^{64}$ Jumar y Paredes, "El comercio intrarregional en el complejo portuario rioplatense...", 40-42.
} 
TEMPUS. Revista en Historia General Medellín (Colombia), 2018, septiembre-octubre, número 8

ISSN: 2422-2976

mostrar "lealtad a la Corona"; así, mientras tanto, la alta burocracia peninsular actuaba sin impedimento alguno". ${ }^{65}$ En el marco de las Guerras Navales se dio detención a una goleta dinamarquesa, nación neutral a la que le estaba permitido el abastecimiento en caso de necesidad, pero en este caso la presa se reportó como exitosa; por lo menos mientras el asunto se mantuvo entre la competencia del comandante guardacostas y el virrey José Amar y Borbón. ${ }^{66} \mathrm{Al}$ remitir a Santafé "los Autos originales obrados con motivo de la detención, que hizo la Goleta Guarda costas de su Magestad titulada la Nanci, a la Dinamarqueza Wiliam, al Norte del Pajaro en la costa de Rio Hacha cargada de Palo de tinte, y cueros, con la Declaratoria de caida en la pena de Comiso con su Cargamento, por resultar justificado"; el argumento había convencido a los revisores del asunto, que se enfocaron en un detalle para dejar en firme la sentencia, para ellos se trataba de "la circunstancia de haverse huido, y arrojado a el Agua el capitan y tripulacion, por cuio hecho descubrieron su culpa y malisia" ${ }^{967}$. En 1804, se envió a la Gobernación de Santa Marta a un militar peninsular miembro de la elite española, Víctor Salcedo y Somodevilla, que llegaba después de atravesar por cargos como Capitán de Infantería en Guayaquil y Gobernador de la Provincia de Antioquia en varias ocasiones, donde inclusive sentó las bases de la actual Universidad de Antioquia. Sin embargo, la carrera de Salcedo allí no fue tranquila y estuvo envuelto en pleitos para alcanzar los ascensos pretendidos o cumplir con sus órdenes. ${ }^{68}$

Pero la batalla de Trafalgar dio al traste con cualquier esfuerzo para alcanzar paridad en el combate naval, el 21 de octubre de 1805, día fatídico para España. ${ }^{69}$ Para nosotros es un detalle en particular el que demuestra hasta qué punto, siglos de arribadas maliciosas, contrabando y refriegas navales dieron como resultado una amalgama de los métodos comerciales. Así, apenas el enemigo fue divisado “al amanecer avisó el

\footnotetext{
${ }^{65}$ Nectalí Ariza Ariza, "Los pecados públicos de doña Luisa Llerena y la justicia del rey en Cartagena de Indias a mediados del siglo XVIII", Anuario de historia regional y de las fronteras 20, n. 1 (2015): 114.

${ }^{66}$ Para un estudio del comercio neutral durante la época. Rodríguez Treviño, "La red del corsario francés Juan Chevallier", 116.

${ }^{67}$ AGN, Aduanas, t. 18, doc, 14. ff, 533v-534r.

${ }^{68}$ Archivo General de Simancas, SGU, LEG,7057,40. ff 287r.

${ }^{69}$ José Manuel Serrano y Allan J. Kuethe, "El astillero de La Habana y Trafalgar", Revista de Indias 67, n. 241 (2007): 763.
} 
del tope, que se descubria una Goleta, que llevaba dos canoas a remolque continuando" y se supo fragata "y aclarando algo los orizontes, que habian estado muy [toscos], se reconoció era una Fragata y dos Goletas, que con toda fuerza de vela se dirigian para nosotros"; en seguida notaron los guardacostas como iba esta enarbolada "en este estado divisamos en la Fragata una bandera al parecer Española, en el tope de Proa, una olandeza en el mayor, y la Ynglesa a Popa”. Sin duda era una embarcación preparada para comerciar con cualquiera que lo necesitara. Después de todo, de acuerdo con los planteamientos de otras tradiciones historiográficas, como los del historiador haitiano Guy Pierre; especialista en ciclos económicos, es necesario repensar los movimientos de independencia en Hispanoamérica en busca de superar lo que define como el efecto de un découpage géographique. De acuerdo con el profesor, este recorte geográfico tiende a generar la exclusión dentro del análisis general del colapso del sistema colonial en la región, de espacios como el Caribe y la zona de América del Norte. Lo que provoca sesgos en los planteamientos, por la manera en que se determina de forma general el punto de arranque de estos movimientos. En consecuencia, el autor define los hechos a partir del 2 de mayo de 1808 en Madrid, como la expresión de las dificultades de España para modernizarse y estar a la par de países como Francia e Inglaterra; donde estaba desarrollado un nuevo sistema comercial. Es conveniente partir de la al final, el valor Guerra de los Siete Años (1756-1763), que por sus características revistió un punto de inflexión. ${ }^{70}$

Así, a principios de 1819, un ultimó comiso presagiaba una crisis para el dominio colonial. Procedente de Jamaica, al mando del capitán don Nicolas Bonolí, la goleta con bandera española Susana fue detenida y se declaró por perdida su carga, que se estableció en "quatrocientas setenta y siete ojas de sables", . La noticia de ingreso del “insurgente Bolivar en Santafé", le fue transmitida al secretario de Estado y Marina por el "Comandante del Apostadero de Cartagena de Yndias", el 15 de septiembre de

\footnotetext{
${ }^{70}$ Guy Pierre, “¿La coyuntura de $1808-1810$ o la guerra de los siete años? Notas por un nuevo método de determinación del punto de inicio de los movimientos de independencia en América Latina", Coloquio internacional Repensar la independencia. Bicentenario de la revolución española, 1808-2008 (Santo Domingo: Academia Dominicana de Historia, 2008), 354-358.

${ }^{71}$ AGN, Miscelánea, t. 104, doc, 11. ff, 95r-96r.
} 
TEMPUS. Revista en Historia General Medellín (Colombia), 2018, septiembre-octubre, número 8

1819. Esta arribó el 19 de febrero de 1820 y textual decía "el 9 de Agosto anterior el Virrey de aquel Reyno se vió precisado a salir de la Capital de Santa Fe huyendo del ynsurgente Bolivar que con sus tropas dispersó la division que mandaba el coronel graduado de Artilleria Don Jose Maria Barreyro, cuyo Gefe quedó en poder del enemigo". 72

\section{Conclusiones}

La ambiciosa pretensión española, para mantener un monopolio comercial con las Indias occidentales, difícilmente pudo haberse materializado. La amplitud del territorio y la excesiva demanda de bienes, para transformar un Nuevo Mundo, nunca supo ser suplida adecuadamente por España; por lo que sus enemigos se le aventajaron. Al parecer, el sistema de galeones tenía fallas internas, que fueron toleradas o tuvieron que serlo; por la incapacidad para erradicarlas. Por ende, las medidas restrictivas fueron superficiales y se enfocaron cada vez más, en los súbditos españoles menos favorecidos. Cuando se introdujeron los navíos sueltos, las naciones extranjeras habían secuestrado los mercados americanos e hicieron leña del árbol caído. La existencia de intereses particulares y la búsqueda de mejores ganancias fueron las bases del sistema comercial moderno, pero España fue la última en reconocerlo.

${ }^{72}$ AGM, Expediciones a Indias, c. 66, doc, 28. ff, 1r-6r. 
Carlos Mario Atehortúa Meneses

Fig. 1. (Izq.) Goleta construida en Norteamerica en una fecha anterior a $1780 .{ }^{73}$

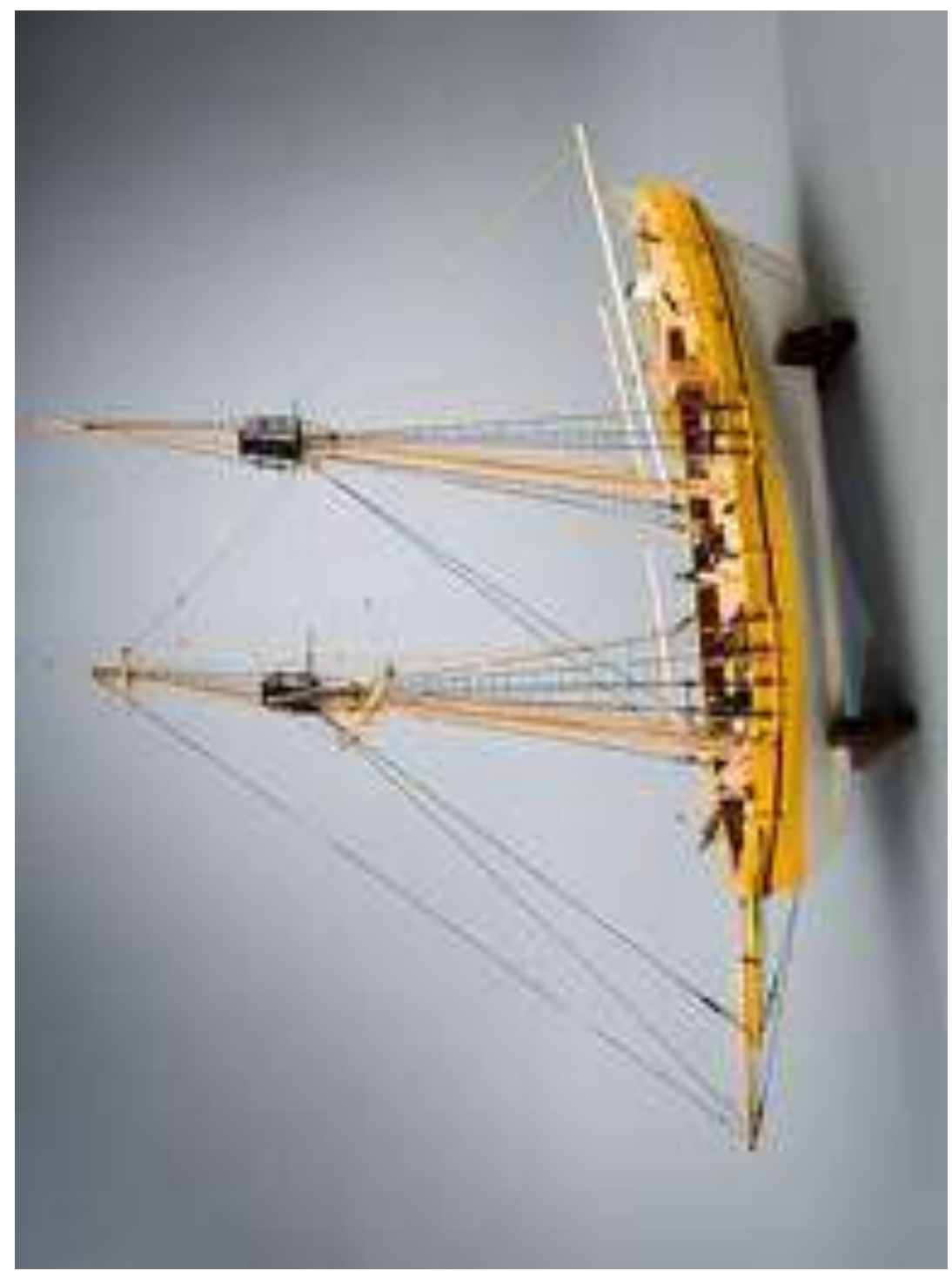

${ }^{73}$ Fue capturada por los británicos en las Antillas durante la revolucion de sus colonias, luego rebautizada con el nombre de HMS Berbice. (Der.) Ejemplar de balandra de la decada de 1760, para maniobrar mejor en aguas calmas esta equipada con remos. Se desconoce su nombre, fue construida en la colonia inglesa de Virginia. National Museum of American History, "En torno al agua. Historias de la América marítima", Guía en idioma español: exhibición en el $1^{\circ}$ pisoala este, Washington D.C., mayo 20, 2009. ff, 6-7. https://americanhistory.si.edu/sites/default/ files/file-uploader/agua.pdf (consultada el 13 de marzo de 2018). 
TEMPUS. Revista en Historia General Medellín (Colombia), 2018, septiembre-octubre, número 8 ISSN: 2422-2976

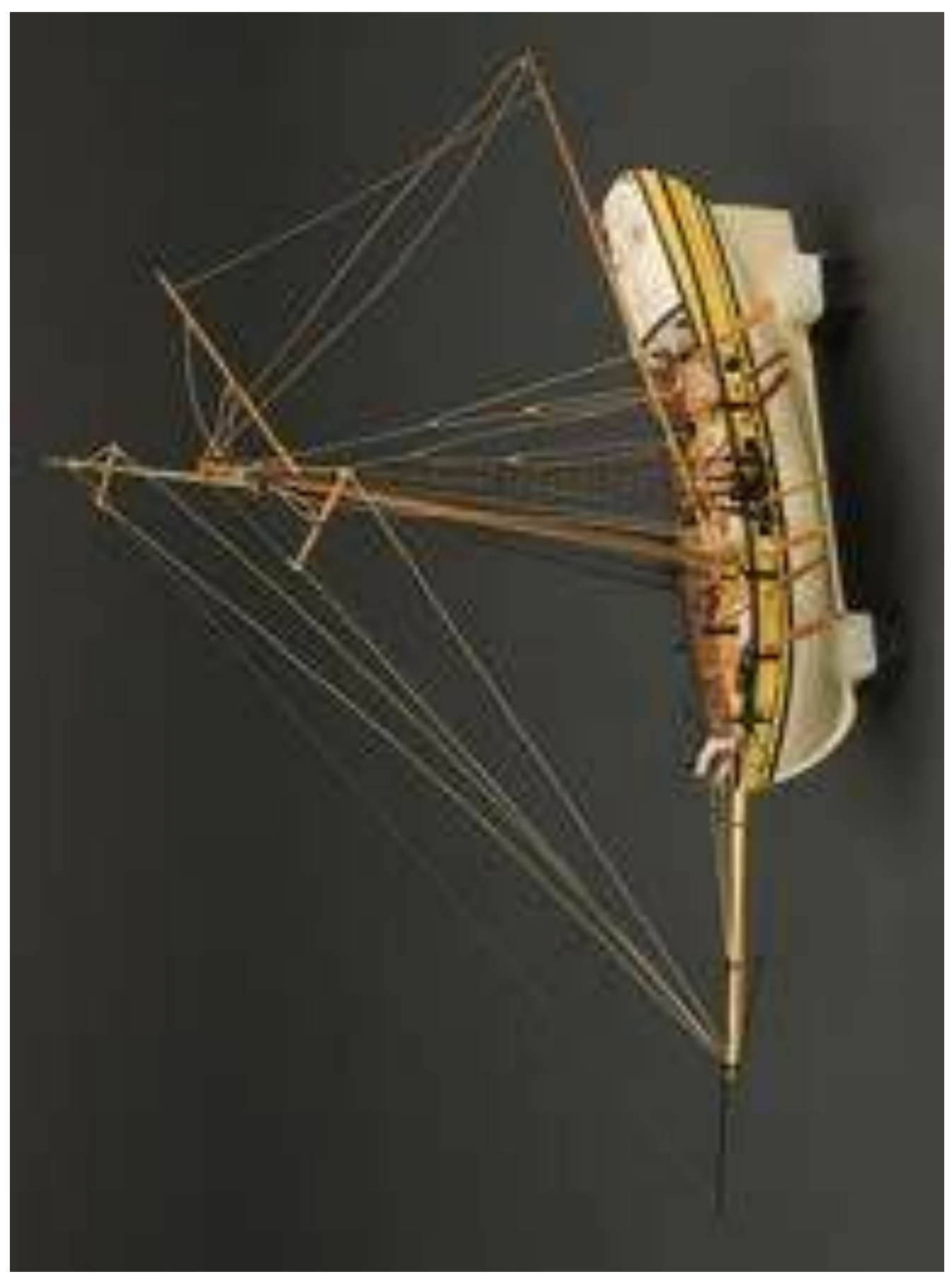


Carlos Mario Atehortúa Meneses

Mapa. 1. Caribe y norte de Suramérica coloniales. ${ }^{74}$

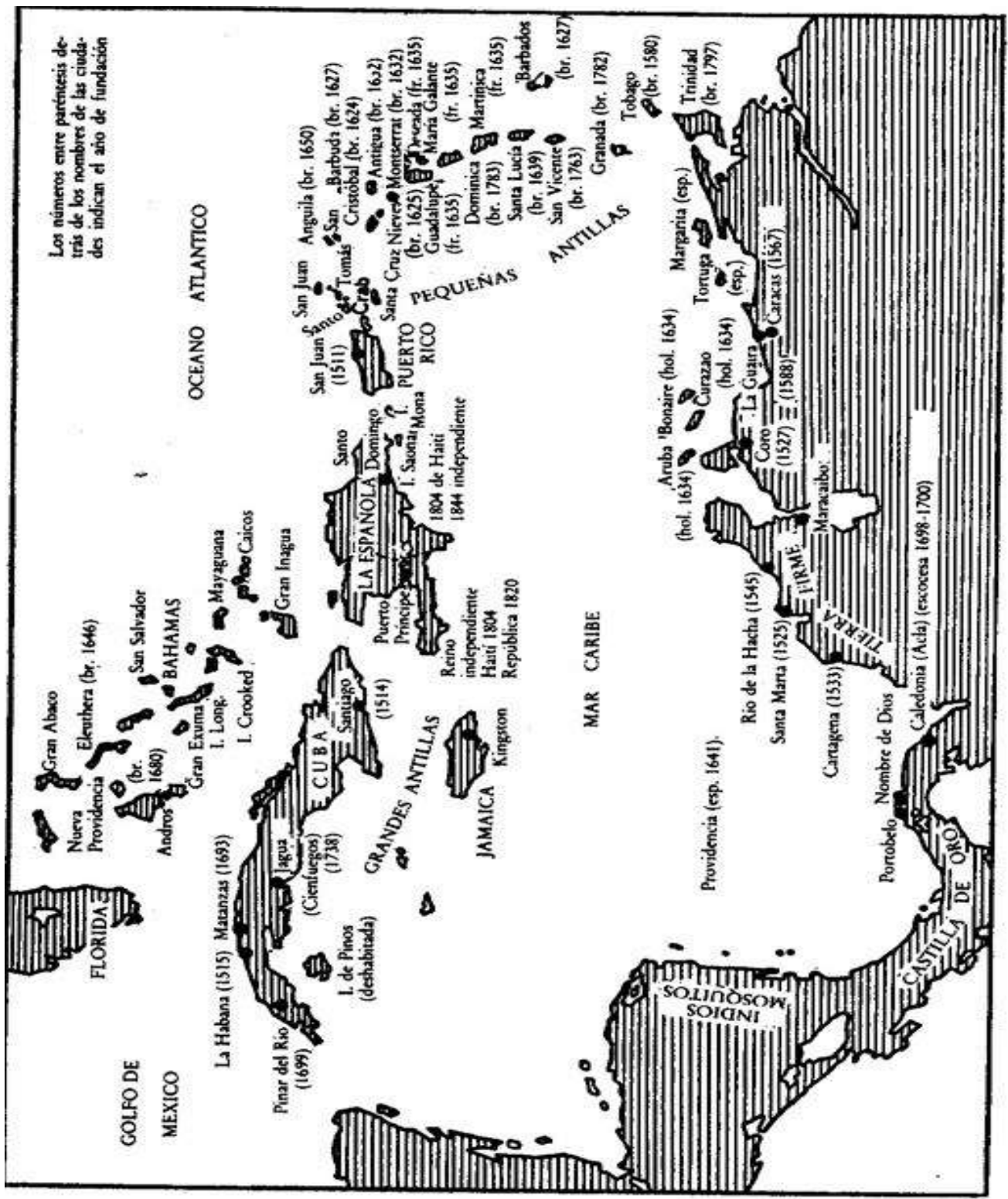

${ }^{74}$ Fieldhouse, Los imperios coloniales, 19. 
TEMPUS. Revista en Historia General Medellín (Colombia), 2018, septiembre-octubre, número 8 ISSN: 2422-2976

\section{Fuentes}

\section{Manuscritas}

Archivo General de la Nación, Colombia (AGN)

Fondos: Aduanas, Milicias y Marina, Miscelánea, Poblaciones.

Archivo General de la Marina “Don Álvaro de Bazán”, España (AGM)

Fondo: Expediciones a Indias.

\section{Periódicos}

El Espectador (Colombia) 2009.

El Tiempo (Colombia) 1995.

The London Gazette (Inglaterra) 1782.

\section{Internet}

americanhistory.si.edu (2018)

web.archive.org (2018)

www.banrepcultural.org (2018)

Www.cuervas-mons.com (2018)

\section{Bibliografía}

Alcedo de, Antonio. Diccionario geográfico-histórico de las Indias occidentales, v. 2. Madrid: Imprenta de Manuel González, 1787.

Amaya Palacios, Sebastián. "Poderío naval en las Indias: las galeras de Cartagena y Manila (1571-1621)". RESI 3, n.2 (2017): 169-188.

Ariza Ariza, Nectalí. "Los pecados públicos de doña Luisa Llerena y la justicia del rey en Cartagena de Indias a mediados del siglo XVIII". Anuario de historia regional y de las fronteras 20, n. 1 (2015): 97-122. 
Bernabé Montalbán, Francisca. "La Real Casa de la Aduana de Madrid”. Trabajo final de ciclo-Universitat per a Majors, Universitat Jaume I, 2009.

Casado Soto, José Luis. "El Cantábrico y las galeras hispanas de la Edad Media a la Moderna". Itsas memoria, n. 4 (2003): 537-552.

Contreras Sánchez, Alicia del C. "El palo de tinte, motivo de un conflicto entre dos naciones, 1670-1802”. Historia mexicana 37, n. 1 (1987): 49-74.

Escobar, Ricardo. "Los criptojudios de Cartagena de Indias: un eslabón en la diáspora conversa”. Anuario colombiano de historia social y de la cultura, n. 29 (2002): 45- 71.

Fieldhouse, David. "Los imperios coloniales antes de 1815". Los imperios coloniales desde el siglo XVIII. México: Siglo XXI Editores, 1984.

Gámez Casado, Manuel. "La pacificación de La Guajira por el ingeniero Antonio de Arévalo. Sobre el proyecto de defensa de Sabana del Valle”. Laboratorio de arte, n. 28 (2016): 373-386.

García de León, Antonio. "Comercio de balandra, contrabando y piratería en el Golfo de México". Orbis incognitvs avisos y legajos del Nuevo Mundo: homenaje al profesor Luis Navarro García, coordinado por Fernando Navarro Antolín. Huelva: Universidad de Huelva, 2007.

Gutiérrez Meza, Ruth Esther. "Orden, poder y contrabando en el Caribe durante el medio siglo antes de la independencia". Palobra, n. 12 (2010): 184-202.

Laurent, Muriel. "Nueva Francia y Nueva Granada frente al contrabando: reflexiones sobre el comercio ilícito en el contexto colonial”. Historia critica, n. 25 (2003): 137-163.

Malagón Pinzón, Miguel. "El consulado de comercio de Cartagena". Estudios sociojurídicos 13, n. 2 (2001): 51-74.

Manzanilla Celis, Ángel Francisco. "Los guardacostas de Cartagena de Indias y la defensa del virreinato del Nuevo Reino de Granada. 1788-1808". Tesis de doctorado, Universidad de Sevilla, 2013. 
TEMPUS. Revista en Historia General Medellín (Colombia), 2018, septiembre-octubre, número 8 ISSN: 2422-2976

Martínez González, Alfredo José. "Bosques y política naval atlántica: las reformas normativas e institucionales de José Patiño (1717-1736)". Revista hispanoamericana, n. 3 (2013): 1-26.

McFarlane, Anthony. "Comerciantes y monopolio en la Nueva Granada. El consulado de Cartagena de Indias". Anuario colombiano de historia social y de la cultura, n. 11 (1983): 43-69.

. "El comercio exterior del virreinato de la Nueva Granada: conflictos en la política económica de los borbones". Anuario colombiano de historia social y de la cultura 6, n. 7 (1972): 69-116.

Meisel Roca, Adolfo. "Entre Cádiz y Cartagena de Indias: La red familiar de los Amador, del comercio a la lucha por la independencia americana". Cuadernos de historia económica y empresarial, n. 12 (2004): 1-30.

Moreno Álvarez, Leonardo Guillermo. "La piratería americana y su incidencia en el Nuevo Reino de Granada, siglos XVI-XVIII: un ensayo bibliográfico". Fronteras de la historia, n. 12 (2013): 373-404.

Newland, Carlos. "Globalización en el imperio español: precios y comercio entre 1661 y 1810". XXII Congreso Internacional de Latin American Studies Association, Hyatt Regency-Miami, 16-18 de marzo, 2000.

Pierre, Guy. “¿La coyuntura de 1808-1810 o la guerra de los siete años? Notas por un nuevo método de determinación del punto de inicio de los movimientos de independencia en América Latina". Ponencia presentada en el Coloquio internacional Repensar la independencia. Bicentenario de la revolución española, 1808-2008, Academia Dominicana de Historia, Santo Domingo, 5-9 de octubre de 2008.

Pradells Nadal, Jesús. "La formación de la Marina española en el siglo XVIII". Canelobre, n. 51 (2006): 44-58.

Ruiz A, Isabel E. "Breve esbozo sobre el comercio ilícito cumanés durante el siglo XVIII". Mañongo 30, n. 16 (2008): 167-180. 
Carlos Mario Atehortúa Meneses

Serrano, José Manuel y Kuethe, Allan J. "El astillero de La Habana y Trafalgar". Revista de Indias 67, n. 241 (2007): 763-776.

Solano de las Aguas, Sergio Paolo. "El Apostadero de la Marina de Cartagena de Indias, sus trabajadores y la crisis política de la Independencia”. Economía y región 9, n. 1 (2015): 209-243.

Vergara S, Ana Johana. "Los vínculos entre la provincia de Caracas y la isla caribeña de San Thomas durante las guerras de independencia (1808-1821)". Anuario de estudios bolivarianos, n. 17 (2010): 169-204.

Villada Cardozo, Diana Cristina. "Objetos convertidos en conceptos: la apropiación del patrimonio arqueológico en el municipio de Nemocón”. Tesis de maestría, Universidad Nacional de Colombia, 2011.

Zafra Caramé, Enrique. "Horatio Nelson versus Blas de Lezo". Revista general de marina 267, n. 3 (2014): 471-480.

Zambrano, Milton. "Piratas, piratería y comercio ilícito en el Caribe: la visión del otro (1550-1650)". Historia Caribe n.12 (2007): 23-56. 